Journal of Materials and Environmental Sciences ISSN : 2028-2508 CODEN : JMESCN

\title{
Chemical composition and in vitro antibacterial activity of the pure essential oils and essential oils extracted from their corresponding hydrolats from different wild varieties of Moroccan thyme
}

\author{
A. Moukhles ${ }^{1}$, A. Ibn Mansour ${ }^{1}$, A. Ellaghdach', J. Abrini' \\ ${ }^{1}$ Laboratory of Applied OrganicChemistry, Department of Chemistry, Faculty of Sciences, University Abdelmalek Essaâdi, \\ M'hanech II, BP 2121 Tetouan 93002, Morocco. \\ ${ }^{2}$ Laboratory of Biology and Health, Department of Biology, Faculty of Sciences, University Abdelmalek Essaâdi, M'hanech \\ II,BP 2121 Tetouan 93002,. Morocco.
}

\section{Received 22 May 2017, Revised 09 Jul 2017 , Accepted 12 Jul 2017}

Keywords

$\checkmark$ Essential oil,

$\checkmark$ Hydrolat,

$\checkmark$ Thymbra capitata,

$\checkmark$ Thymus munbyanus,

$\checkmark$ Thymus glandulosus,

$\checkmark$ Antibacterial activity,

$\checkmark$ GS/MS

mou231073@gmail.com , Phone: (+2) 699104070

\section{Abstract}

This work was designed to study the chemical composition and antibacterial activity, against four bacterial strains including two Gram-negative and two Gram-positive of pure essential oils, and those extracted from corresponding hydrolats of three species of Moroccan Thymus: (Thymbra capitata, Thymus munbyanus and Thymus glandulosus). Analysis of these oils by GS/MS, revealed that the pure essential oil of Thymbra capitata (carvacrol chemotype) is dominated by carvacrol $(85,35 \%)$ and the essential oil extracted from its hydrolat (carvacrol /4-tert-butylcatechol chemotype) consists predominantly of carvacrol $(75.14 \%)$, 4-tert-butylcatechol $(14.72 \%)$ and thymol $(4.36 \%)$. Thus, the pure essential oil of Thymus munbyannus (carvacrol/p-cymene/ $\gamma$-terpinene chemotype) consists mainly of carvacrol (44.52\%), $p$-cymene $(16.64 \%)$ and $\gamma$-terpinene $(10.85 \%)$, while the essential oil extracted from its hydrolat (carvacrol/thymoquinone/borneol/linalyl anthranilate chemotype) consists especially of carvacrol (36.94\%), thymoquinone $(10.79 \%)$, borneol $(10.21 \%)$ and linalyl anthranilate (15.78\%). The chemical composition of pure essential oil of Thymus glandulosus (thymol/carvacrol/ $p$-cymene chemotype) shows that this latter consists mainly of monoterpenes especially both phenolic compounds thymol $(28.51 \%)$ and carvacrol (24.88\%) along with their precursors $p$-cymene $(18.57 \%)$ and $\gamma$-terpinene $(10.51 \%)$, while the essential oil extracted from its hydrolat (carvacrol/thymol chemotype) consists mainly of carvacrol (45.95\%), thymol (44.68\%) and 4-tert-butylcatechol $(3.87 \%)$. These oils showed significant antibacterial activities against the bacterial strains tested.

\section{Introduction}

Since long time ago, medicinal and aromatic plants were still considered a use of the humanity for healing and culinary interests. In Chinese and Indian civilizations, we discover hints of extremely old therapeutic utilization of plants [1,2]. Until today, the Moroccan medicinal flora is still unknown, due to the huge number of plant species of this later, the current assessment for all vascular plants does not exceed some hundreds of medicinal species. [3]. The number of Moroccan medicinal plants not exceeding 600 species [4], (14.28\% of total of Moroccan flora) is far from exhaustive and suggests that many medicinal plants remain to be discovered in different regions of Morocco by ethnobotanical and therapeutic studies. For this purpose, previous works have focused on the study of biological activity of some medicinal plants in Morocco [5-8]. Bellakhdar J. (1997), reported a summary about crucial importance entitled: traditional Moroccan pharmacopoeia [9].

Within the Labiate's family, with about 250 genera, the genus Thymus is one of the eight most important genera with regard to the number of species included [10]. Nevertheless, this number varies depending on the taxonomical character. The thyme is an aromatic plant used for medicinal and spice purposes almost everywhere in the world. The genus thymus is very frequent in the Mediterranean areas, where some species form a special type of bushy vegetation not more than 50cm high, well adapted to warm and dry summer weather [11]. 
The First Edition of Brazilian Official Pharmacopoeia (1926) reported 1702 monographs for medicinal products, where two monographs refer to the thyme [12]. Near 100 types of thymus have been identified over the world [13]. The essential oils of many species have been studied for a long time [14-21], also has proven some biological effects such as antispasmodic [22], antibacterial [23-25], antifungal [26,27], anti-tabagism [28], antioxidant activities [29] and antimicrobial [30].

In Morocco, the thyme (Lamiaceae) is represented by 21 species within 12 are endemic [31]. It has been utilized as a part of Moroccan traditional medicine for the treatment of several medical troubles as diarrhoea, fever, cough, infected areas and wounds. It has also been used as a tonic and stimulant $[32,33]$. Generally, it has been used for its anti-inflammatory properties after topical or oral administration [34-36], antibacterial and antifungal properties [37, 38]. These species are locally known under the common name "Zaetra" in Arabic (Moroccan dialect) and "Azoukeni" in Tamazight.

The aim of the present study was to evaluate the chemical composition of different varieties of Thymus (Thymbra capitata, Thymus mumbyanus and Thymus glandulosus ), pure essential oils and essential oils extracted from their corresponding hydrolats. This latter were isolated by hydrodistillation from the aerial parts of plants collected from different localities in Morocco. Therefore to determine their antibacterial powers against four microorganisms including two Gram-negative (Escherichia coli K12 and Proteus mirabilis) and two Gram-positive (Bacillus subtilis DCM 6633 and Staphylococcus aureus).

\section{Materials and methods}

\subsection{Plant material and essential oil extraction}

The aerial parts of Thymbra capitata, Thymus munbyanus and Thymus glandulosus were collected at flowering stage (early May 2014) from their wilds habitat respectively in the regions: (Tetouan) for an altitude of $121 \mathrm{~m}$ to North, (Rif) for an altitude of $288 \mathrm{~m}$ to the North-East, and (Tizi Nisly-Beni mellal) for an altitude of $1596 \mathrm{~m}$ to the centre. The identification was confirmed by Professor Mohamed Kadiri (Department of Biology, Faculty of Sciences, Tetouan, Morocco). The collected materials were air-dried at room temperature $\left(\approx 25^{\circ} \mathrm{C}\right)$ in the shade and subjected to hydrodistillation using a Clevenger type distillation apparatus for 3 hours. The obtained oils were dried with anhydrous sodium sulfate, weighed and stored at $4{ }^{\circ} \mathrm{C}$ until use.

\subsection{Extraction of essential oils from hydrolats.}

During the process of extracting essential oils using the hydrodistillation method, the distillate condenses in contact with the cold walls of a cooling down. Essential oil then, dissociates spontaneously hydrolat for their immiscibility. However, a small part of polar odor molecules with hydrophilic nature remains soluble in this hydrolat. The hydrolats were usually observed as a waste of hydrodistillation and have been neglected by the scientific community. Nevertheless, studies have shown that hydrolats of some plants have significant therapeutic properties and are often different from those of the corresponding essential oils. Which explains the remarkable interest that has recently appeared on the use of these hydrolats for therapeutic purposes $[39,40]$.

Thus, some works recently focused on the latest interest in hydrolats. Moreover, these studies show very promising results on the pharmacological potential of the extract types.

The remaining oils in hydrolat were obtained after a liquid-liquid extraction of the hydrolat with an organic solvent [41]. The recovered organic phase was dried by anhydrous sodium sulfate and then the oily residue was obtained after removal of solvent under reduced pressure by rotary evaporator.

\subsection{Chromatographic analysis}

Essential oil samples $(0.1 \mu \mathrm{L})$ were injected neat into an HP 6890 gas chromatography equipped with a flame ionisation detector (FID) and a $30 \mathrm{~m}$ x $0.25 \mathrm{~mm}$ HP-5 (cross-linked Phynel-Methyl Siloxane) column with $0.25 \mu \mathrm{m}$ film thickness (Agilent), was used for the study. Helium was used as carrier gas, the flow through the column was $1,4 \mathrm{~mL} \mathrm{~min}^{-1}$ and the splitless mode was used. The column was maintained at $40^{\circ} \mathrm{C}$ for $5 \mathrm{~min}$, increased to $230^{\circ} \mathrm{C}$ at rate of $10^{\circ} \mathrm{C} \mathrm{min}^{-1}$ and finally raised from 230 to 280 at rate of $30^{\circ} \mathrm{C} \mathrm{min}^{-1}$.

The oil was analysed by gas chromatography-mass spectrometry (GC-MS) using a Hewlett Packard 6890 mass selective detector coupled with a Hewlett Packard 6890 gas chromatograph. The MS operating parameters were as follows: ionisation potential, $70 \mathrm{eV}$; ionisation current, $2 \mathrm{~A}$; ion source temperature, $200^{\circ} \mathrm{C}$, resolution, 1000. Mass unit were monitored from 30 to $450 \mathrm{~m} /$ z. Identification of components in the oil was based on retention indices relatives to n-alkanes and computer matching with the WILLEY 275. L library, as well as by comparison of the fragmentation patterns of mass spectra with those reported in the literature. The chromatographic conditions were identical to those used for GC analysis. 


\subsection{Antibacterial activity}

\subsubsection{Bacterial strains}

Four bacterial references strains were used: Escherichia coli K12 and Staphylococcus aureus (Laboratory of Food Microbiology, UCL, Belgium: MBLA), Proteus mirabilis (Institute of Hygiene, Rabat, Morocco: IH), Bacillus subtilis DCM 6633 (German Collection of Micro-organisms: DCM). Bacterial strains were grown in LB broth and incubated at $37^{\circ} \mathrm{C}$.

\subsubsection{Minimum inhibitory and minimum bactericidal concentrations}

Due to immiscibility of essential oils to the water and therefore the culture medium, all tests were performed in LB broth supplemented with bacteriological agar $(0.15 \%(\mathrm{w} / \mathrm{v}))$. Serial twofold dilutions, ranging from 2 to $0.0019 \%(\mathrm{v} / \mathrm{v})$ of the essential oil, were prepared in a $96-$ well microtitre plate, volume being $50 \mu \mathrm{L}$. Then 50 of LB $(0.15 \% \mathrm{w} / \mathrm{v})$ inoculated with tested bacteria were added onto microplates. Final cellular concentration was 106 $\mathrm{cfu} / \mathrm{mL}$. Plates were incubated at $37^{\circ} \mathrm{C}$ for $18 \mathrm{~h}$. At that time, $5 \mu \mathrm{L}$ of resazurin were added to the wells. After incubation at appropriate temperature for $2 \mathrm{~h}$, the minimum inhibitory concentration (MIC) was then determined as the lowest essential oil concentration prevented change of coloring of resazurin. The minimum bactericidal concentration (MBC) corresponded to the lowest concentration of the essential oil, yielding negative subcultures after incubation at appropriate temperature for $24 \mathrm{~h}$. It is determined in broth dilution tests by subculturing $10 \mu \mathrm{L}$ from negative wells on PCA medium [42].

\section{Results and discussion}

\subsection{Yields of essential oils.}

The yields of pure essential oils and those extracted from corresponding hydrolats were calculated according to the plant material of the dried aerial parts $(1 \mathrm{Kg})$. These later were laying eight days of three species of thymus collected (Thymbra capitata, Thymus munbyanus and Thymus glandulosus).

As reported in table 1, the yield of essential oil of Thymbra capitata is the highest where its rate reaches $1.99 \%$, followed by essential oil of Thymus glandulosus with $1.54 \%$ and then Thymus munbyanus with a relatively low rate of $0.39 \%$.

Moreover, the relative yields of essential oils extracted from hydrolats are proportional to those of corresponding pure essential oils: $0.45 \%$ for Thymbra capitata, $0.15 \%$ for Thymus glandulosus and $0.09 \%$ for Thymus munbyanus.

Table 1: Relative yields to the pure essential oils and those extracted from the corresponding hydrolats.

\begin{tabular}{|c|c|c|c|c|}
\hline \multirow{2}{*}{ Specie } & \multicolumn{2}{|c|}{ Volume (ml) } & \multicolumn{2}{c|}{ yield \% } \\
\cline { 2 - 5 } & EOp & EOe & EOp & EOe \\
\hline Thymbra capitata & 19.98 & 4.54 & 1.99 & 0.45 \\
\hline Thymus glandulosus & 15.44 & 1.51 & 1.54 & 0.15 \\
\hline Thymus munbyanus & 3.97 & 0.88 & 0.39 & 0.09 \\
\hline
\end{tabular}

EOp : pure essential oil ; EOe : extracted essential oil from hydrolat

\subsection{Chemical composition of essential oils.}

Based on GC and GC-MS analysis of the Thymbra capitata pure essential oil (carvacrol chemotype), 21 components were identified, which represented $98.21 \%$ of the total detected constituents (Table 2). This essential oil was characterized by the high monoterpenes fraction, and especially by the presence of the phenolic carvacrol $(85.35 \%)$, along with other components to relatively low levels of their precursors $p$-cymene $(4.16 \%)$ and $\gamma$-terpinene $(2.08 \%)$ and also $\beta$-caryophyllene (2.17\%). Bounatirou et al. (2007) analyzed the chemical composition of essential oils isolated from the aerial parts of Tunisian Thymus capitatus (today Thymbra capitata) during the different phases of the plant development. The main components of the essential oils were carvacrol (62-83\%), $p$-cymene (5-17\%), $\gamma$-terpinene (2-14\%) and $\beta$-caryophyllene (1-4\%) [43] . Results of similar study, Ibraliu et al. (2011) studied the essential oil composition of Thymbra capitata collected from different agroclimatically diverse sites in Albania. They reported that the main components were carvacrol (54-78\%), $p$-cymene (5-8.4\%) and $\gamma$-terpinene (2.6-4\%) [44]. In similar studies, Thymbra capitata essential oil from Spain have carvacrol as the most abundant component (74.3-78.3\%) [45]. So, these results are in concordance with our study (Table 2). However, that from Turkey was less enriched in carvacrol (35.6\%) along with thymol (18.6\%), $p$ cymene (21\%) and $\gamma$ - terpinene (12.3\%) [46]. On the contrary, that from Sardaigne was mainly constituted by thymol (29.03\%) followed by $p$-cymene (26.4\%) while carvacrol represents only $10.8 \%$ of the total oil [47]. 
Table 2: Quantitative and qualitative compositions of Thymus species essential oils.

\begin{tabular}{|c|c|c|c|c|c|c|c|}
\hline & \multicolumn{6}{|c|}{ PA $\%$} \\
\hline $\mathbf{R T}(\min )$ & Compound Name & EOp.TC & EOp.TG & EOp.TM & EOe.TC & EOe.TG & EOe.TM \\
\hline 7.28 & 1R- $\alpha$-Pinene & 0.32 & 0.91 & 1.17 & - & - & - \\
\hline 7.69 & Camphene & 0.09 & 1.16 & 1.83 & - & - & - \\
\hline 8.43 & $\beta$-Ocimène & 0.11 & 0.26 & 0.40 & - & - & - \\
\hline 8.74 & $\Delta 3$-Carene & 0.53 & 0.68 & 0.60 & - & - & - \\
\hline 9.15 & $\beta$-Phellandrene & 0.12 & 0.13 & 0.14 & - & - & - \\
\hline 9.34 & 2-Carene & - & 0.05 & 0.05 & - & - & - \\
\hline 9.50 & Terpinolene & 0.65 & 1.41 & 1.53 & - & - & - \\
\hline 9.74 & p-Cymene & 4.16 & 18.57 & 16.64 & 0.46 & 0.27 & 0.12 \\
\hline 9.88 & Limomene & 0.21 & 0.38 & 0.35 & - & - & - \\
\hline 10.05 & Phenyl methanol & - & - & - & - & - & 0.18 \\
\hline 10.70 & $\gamma$-Terpinene & 2.08 & 10.51 & 10.85 & 0.05 & 0.06 & - \\
\hline 10.95 & trans Sabinene hydrate & 0.06 & 0.20 & 0.30 & - & 0.05 & - \\
\hline 11.55 & 1,2-Oxolinalool & 0.07 & 0.16 & 0.14 & - & 0.10 & 0.09 \\
\hline 11.84 & Linalyl anthranilate & 0.95 & 1.85 & 0.52 & 0.42 & 0.59 & 15.78 \\
\hline 12.08 & 2,4-Hexadiene, 2,3-dimethyl- & - & - & 0.09 & - & - & - \\
\hline 12.15 & 1-Octen-3-yl-acetate & - & - & - & - & - & 0.10 \\
\hline 12.50 & cis Sabinene hydrate & - & - & - & - & - & 0.09 \\
\hline 13.06 & 2(10)Pinen-2-ol & - & - & - & - & - & 0.12 \\
\hline 13.23 & $\alpha$-Campholenal & - & 0.09 & 0.58 & - & - & - \\
\hline 13.26 & Camphor & - & - & - & - & 0.06 & 5.38 \\
\hline 13.82 & Borneol & 0.23 & 3.75 & 4.01 & 1.85 & 2.90 & 10.21 \\
\hline 14.12 & 4-Terpinol & 0.40 & 0.55 & 0.44 & 0.16 & 0.32 & 1.84 \\
\hline 14.31 & $p$-Cymen-8-ol & - & - & 0.06 & 0.14 & 0.12 & 0.19 \\
\hline 14.49 & $\alpha$-Terpineol & 0.06 & 0.08 & 0.06 & - & - & - \\
\hline 14.54 & 4-Terpinyl acetate & - & - & - & - & 0.07 & 3.33 \\
\hline 14.70 & cis- Limonene oxide & - & - & 0.09 & - & - & 0.1 \\
\hline 14.91 & $\begin{array}{c}\text { 3-Cyclohexene-1-carboxaldehyde, } \\
\text { 1,3,4-trimethyl- }\end{array}$ & - & - & 0.09 & - & - & - \\
\hline 15.29 & trans-2-Caren-4-ol & - & - & - & - & - & 0.07 \\
\hline 15.56 & Isobornyl formate & - & - & - & - & - & 0.49 \\
\hline 15.67 & Thymol methyl ether & - & - & 0.96 & - & - & - \\
\hline 15.90 & Isothymol methyl ether & - & 0.08 & 1.42 & - & - & 0.34 \\
\hline 16.13 & Thymoquinone & - & - & 0.05 & - & - & 10.79 \\
\hline 17.04 & p-Thymol & - & 0.11 & - & 0.24 & 0.23 & - \\
\hline 17.12 & Saltolina triene & - & - & - & - & - & 0.57 \\
\hline 17.24 & Thymol & 0.22 & 28.51 & 2.18 & 4.36 & 44.68 & 1.83 \\
\hline 17.49 & Carvacrol & 85.35 & 24.88 & 44.52 & 75.14 & 45.95 & 36.94 \\
\hline 19.65 & Hydroquinone-2,5-di-tert-butyl & - & - & - & 0.06 & - & 1.09 \\
\hline 20.42 & $\alpha$-Gurgujene & - & 0.14 & 0.07 & - & - & - \\
\hline 20.69 & $\beta$-Caryophyllene & 2.17 & 2.28 & 6.39 & 0.17 & - & 0.58 \\
\hline 21.17 & 4-tert-butyl Catechol & 0.11 & 0.32 & - & 14.72 & 3.87 & - \\
\hline 21.54 & $\alpha$-Guaiene & 0.06 & 0.07 & 0.15 & - & - & - \\
\hline 22.21 & Germacrene D & - & - & 0.71 & - & - & - \\
\hline 22.61 & $\gamma$-Muurolene & - & 0.25 & 0.29 & - & - & 0.08 \\
\hline 22.98 & $\gamma$-Cadinene & - & 0.06 & 0.07 & - & - & 0.18 \\
\hline 23.19 & $\delta$-Cadinene & - & 0.18 & 0.29 & 0.06 & - & 0.07 \\
\hline 24.54 & (-)-Spathulenol & - & 0.25 & - & 0.27 & - & 0.11 \\
\hline 24.69 & Caryophyllene oxide & 0.26 & 0.24 & 0.45 & 0.17 & - & 1.02 \\
\hline 24.89 & $\gamma$-Gurjunene & - & - & 0.07 & - & - & 0.16 \\
\hline 25.38 & Cubenol & - & - & - & - & - & 0.22 \\
\hline 25.93 & $\beta$-Guaiene & - & - & - & 0.07 & - & 3.65 \\
\hline 26.26 & T-Cadinol & - & - & 0.07 & 0.11 & - & 0.12 \\
\hline 26.62 & Aromadendrene oxide & - & - & - & - & - & 0.08 \\
\hline 26.82 & $\beta$-Longipinene & - & - & - & - & - & 1.10 \\
\hline & & $98.21 \%$ & $98.57 \%$ & $97,63 \%$ & $98,45 \%$ & $99,27 \%$ & $97,02 \%$ \\
\hline
\end{tabular}

RT: Retention time in minutes, PA: peak area. EOp.TC: pure essential oil of Thymbra capitata ; EOp.TG: pure essential oil of Thymus glandulosus, EOp.T.M : pure essential oil of Thymus munbyanus; EOe.TC : extracted essential oil from Thymbra capitata hydrolat; EOe.TG : extracted essential oil from Thymus glandulosus hydrolat; EOe.TM : extracted essential oil from Thymus munbyanus hydrolat. 
30 components were identified in Thymus glandulosus pure essential oil (thymol/carvacrol/p-cymene chemotype) amounting to $98,57 \%$ of the total oil (Table 2). It was mainly constituted by monoterpenes especially both phenolic compounds thymol $(28.51 \%)$ and carvacrol $(24.88 \%)$, beside their precursors $p$-cymene $(18.57 \%)$ and $\gamma$-terpinene $(10.51 \%)$. The chemical composition obtained in this study is different in relation to that reported by Adzet T. et al. (1989), who studied the chemical composition of the Thymus glandulosus essential oil from Spain. The main compounds identified were $P$-cymene (58\%), borneol (8.7\%), $\alpha$-pinene $(7.2 \%)$, camphene $(5.3 \%)$ and verbenone (4\%), while the phenols were present in low levels: thymol $(2,4 \%)$ and carvacrol $(0,5 \%)$ [48]. In a similar study, Chebli B.et al. (2003) analyzed Thymus glandulosus essential oil from Morocco (thymol/p-cymene chemotype) and found as its major constituents were thymol (43.2\%), p-cymene (35.7\%) and carvacrol (1.7\%) [49].

On the other hand, 36 compounds were identified in Thymus munbyanus pure essential oil (carvacrol/ $p$-cymene/ $\gamma$-terpinene chemotype), which accounted for $97.63 \%$ of the total oil (Table 2). The major components were carvacrol (44.52\%), $p$-cymene $(16.64 \%)$ and $\gamma$-terpinene $(10.85 \%)$, along with other components to relatively low levels of borneol (4.01\%) and the sesquiterpene $\beta$-caryophyllene (6.39\%). In concordance with this study, the Thymus munbyanus essential oil from Algeria analyzed by Benchabane (2012) was characterized by a large amount of carvacrol $(35.2 \%)$ followed by thymol $(18.5 \%), \alpha$-terpineol $(7.6 \%), p$-cymene $(5.1 \%)$ and $\gamma$-terpinene $(7 \%)$ [50]. However, the essential oils of Thymus munbyanus from various regions in Morocco (Itzer, Tizint lghamet and Dar Ait Mbarek) analyzed by Belmalha S. (2015), record different chemical compositions and revealed presence of main compounds with variable rates: camphre (24.87-21.83-36.63\%), 1.8-cineole (11.88-15.68-11.79\%), camphene (17.34-13.48-16.83\%), $\alpha$-pinene (11.26-10.82-9\%) and borneol (6.88-5.15-3.58\%) respectively, where there is a total absence of phenolic compounds [51]. The remarkable difference of Thymus munbyanus essential oils chemical composition from region to other confirms that this genus of plant displays a very important chemical polymorphism. Benjilali et al. proved that the chemical profile of Thymus munbianus essential oil from different regions of Morocco varies according to the origin of the plant: thymol (0.3-29.3\%), carvacrol (0.4-21.7\%), $\alpha$-terpinyl acetate $(0-42.9 \%)$, geranyl acetate $(0-21.7 \%)$, geranyl butyrate $(0-26.7 \%)$, camphre $(0.4-28.4 \%)$ and borneol (0.1-31.6\%) [38].

The diversity of chemotypes in the Thymus essential oils depends on several factors and especially genetic and ecological (biotic, abiotic) [52-54].

GS/ SM analysis of the essential oil extracted from Thymbra capitata hydrolat (carvacrol/4-tert-butylcatechol chemotype) led to the identification and quantification of 17 components which accounted for (98.45\%) of the total oil (Table 2), and the phenolic compounds constituted the major fraction of the oil $(94.22 \%)$ with carvacrol (75.14\%) being the most abundant component followed by 4-tert-butylcatechol (14.72\%) and thymol (4.36\%).

A total of 14 components were identified representing $99.27 \%$ of the total oil extracted from Thymus glandulosus hydrolat (carvacrol/thymol chemotype), phenolic monoterpenes were indicated to be the main group of constituents $(94.5 \%)$, with carvacrol (45.95\%), thymol (44.68\%) and 4-tert-butylcatechol (3.87\%) being the major ones (Table 2).

In the essential oil extracted from Thymus munbyanus hydrolat (carvacrol /thymoquinone/borneol/linalyl anthranilate chemotype), 33 components were identified representing 97.02\% of the total oil (Table 2). The oxygenated monoterpenes constituted the major fraction of the oil $(82.75 \%)$ with carvacrol $(36.94 \%)$ being the most abundant components followed by linalyl anthranilate (15.78\%), thymoquinone (10.79\%), borneol (10.21\%), camphor (5.38\%) and $\beta$-guaiene (3.65\%).

\subsubsection{Comparison of the chemical composition of pure essential oils and those extracted from corresponding} hydrolats:

As reported in table 2, the essential oil of Thymbra capitata hydrolat is characterized by a sharp increase in the percentage of 4-tert-butylcatechol, varies from $0.11 \%$ in the pure essential oil to $14.72 \%$ in the extracted oil from corresponding hydrolat, this later indicated this molecule has an important hydrophilic power.

However, carvacrol represented in pure essential oil with a percentage of $85.35 \%$ indicating a rate of $75.14 \%$ in the hydrolat oil. Therefore, we note a total disappearance or a nearly disappearance of monoterpene hydrocarbons in hydrolat especially $p$-cymene and $\gamma$-terpinene.

The comparison between chemical composition of Thymus glandulosus pure essential oil and extracted oil from corresponding hydrolat, reveals as expected, an almost disappearance of $p$-cymene and $\gamma$-terpinene: varies respectively between $(18.57 \%-10.51 \%)$ in pure essential oils to $(0.27 \%-0.06 \%)$ in extracted oils from hydrolats. Moreover, a sharp increase in the percentage of phenolic components thymol, carvacrol and 4-tert-butylcatechol which moved up respectively from (28.51- 24.88- $0.32 \%$ ) in pure essential oil to (44.68-45.95-3.87\%) in extracted 
oil from hydrolat. In harmony with above, there was a lack of $p$-cymene and $\gamma$-terpinene in extracted essential oil from Thymus munbyanus hydrolat. Moreover, a decrease of thymol and $\beta$-caryophyllene followed by appearance or increase of rates of the constituents such as linalyl anthranilate, camphor, borneol, 4-terpinyl acetate, thymoquinone and $\beta$-guaiene, moving up respectively from $(0.52 \%-0 \%-4.01 \%-0 \%-0.05 \%-0 \%)$ in pure essential oil to $(15.78 \%-5.38 \%-10.21 \%-3.3 \%-10.79 \%-3.65 \%)$ in oil extracted from corresponding hydrolats.

Generally, the chemical composition of extracted oils from hydrolats deviates from the corresponding pure essential oils. Extracted oils from hydrolats are permanently enriched in oxygenated molecules with high hydrophilic nature especially phenols, whereas the lipophilic constituents such as terpene hydrocarbons are found more often as traces or absent.

\subsection{Determination of minimum inhibitory concentration (MIC) and minimum bactericide concentration (MBC).}

Table 3. Antibacterial activity of the pure essential oils and their corresponding extracted oils from hydrolats of Thymus species in solid and liquid media.

\begin{tabular}{|c|c|c|c|c|c|c|c|c|c|c|c|c|c|}
\hline \multirow{2}{*}{} & \multicolumn{4}{|c|}{ Pure essential oils } & \multicolumn{4}{c|}{ Essential oils extrated from hydrolats } \\
\cline { 2 - 16 } & \multicolumn{3}{|c|}{ MIC (v/v) } & \multicolumn{3}{c|}{ MBC (V/V) } & \multicolumn{3}{c|}{ MIC (v/v) } & \multicolumn{3}{c|}{ MBC (v/v) } \\
\hline \multicolumn{2}{|c|}{ BACTERIES } & T.C & T.G & T.M & T.C & T.G & T.M & T.C & T.G & T.M & T.C & T.G & T.M \\
\hline GRAM- & $\boldsymbol{E}$.coli & 0.062 & 0.125 & 0.125 & 0.125 & 0.125 & 0.125 & 0.031 & 0.062 & 0.031 & 0.031 & 0.062 & 0.125 \\
negative & Pr. Mirabilis & 0.062 & 0.125 & 0.125 & 0.125 & 0.250 & 0.125 & 0.031 & 0.062 & 0.031 & 0.031 & 0.062 & 0.125 \\
\hline GRAM- & B.subtilis & 0.031 & 0.062 & 0.125 & 0.062 & 0.062 & 0.125 & 0.031 & 0.062 & 0.062 & 0.031 & 0.250 & 0.125 \\
positive & S. aureus & 0.031 & 0.125 & 0.125 & 0.125 & 0.125 & 0.125 & 0.031 & 0.062 & 0.062 & 0.031 & 0.125 & 0.125 \\
\hline
\end{tabular}

T.C : Tymbra capitata ; T.G : Thymus glandulosus; T.M : Thymus munbyanus; E.Coli : Escherichia coli K12; S. aureus : Staphylococcus aureus ; B. subtilis : Bacillus subtilis ; Pr. mirabilis : Proteus mirabilis

\subsection{1 : Antibacterial activity of the pure essential oils.}

Both Gram-positive bacterial strains showed high sensitivity to the pure essential oil of Tymbra capitata: strains of B. subtilis and S. aureus were inhibited from a minimum inhibitory concentration $(\mathrm{MIC}=0.031 \mathrm{v} / \mathrm{v})$, while the other two Gram-negative strains E. coli and Pr. mirabilis have been inhibited from a concentration (MIC $=0.062 \mathrm{v} / \mathrm{v})($ Table 3$)$. The strong antibacterial activity of the pure essential oil of Thymbra capitata is rather due to its chemical profile rich in carvacrol (85.35\%) which is known for its antibacterial power [55]. The same results were obtained for essential oil of Thymbra capitata (L) Hoffm.\& Link from Morocco [carvacrol (70.92\%), $p$ cymene $(6.34 \%)$ and $\gamma$-terpinene $(4.92 \%)$ ] against bacterial strains E. coli $(\mathrm{MIC}=0.05 \mathrm{v} / \mathrm{v})$, B. subtilis $(\mathrm{MIC}=$ $0.033 \mathrm{v} / \mathrm{v}$ ) and $S$. aureus (MIC $=0.05 \mathrm{v} / \mathrm{v}$ ) [56]. Similarly, the essential oil of Thymus vulgaris, comprises almost the same chemical composition as the studied Thymbra capitata [carvacrol $(83.8 \%), \gamma$-terpinene (4.96\%) and $p$ cymene (8.15\%)], showed great antibacterial effect [57]. Also, Bouzouita et al.(2003) previously Studied the antimicrobial activity of essential oils from Tunisian aromatic plants against two bacterial strains (Lactobacillus plantarum and Escherichia coli) using a submerged broth cultivation method. The results obtained showed that Thymbra capitata oils were one of the greatest inhibitors of all the strains tested [58] which is in agreement with our results.

The pure essential oil of Thymus glandulosus exercised a great antibacterial effect against four strains tested. It inhibited the B. subtilis strain from the concentration of $(\mathrm{MIC}=0.062 \mathrm{v} / \mathrm{v})$, while other strains were inhibited at a concentration of $(\mathrm{MIC}=0.125 \mathrm{v} / \mathrm{v})$ (Table 3$)$. This efficiency is due to its richness in phenolic compounds: thymol (25.51\%) and carvacrol (24.88\%). Thus, the pure essential oil of Thymus munbyanus, rich in carvacrol (44.52\%), exerted an antibacterial effect almost similar to that of the pure essential oil of Thymus glandulosus which inhibiting all strains from the concentration $(\mathrm{MIC}=0.125 \mathrm{v} / \mathrm{v})($ Table 3$)$ without neglecting the importance of the terpene hydrocarbons $p$-cymene and $\gamma$-terpinene represented in these oils with significant percentages: (18.57$10.51 \%)$ in a pure essential oil of Thymus glandulosus and (16.64- 10.85\%) in a pure essential oil of Thymus munbyanus respectively. Carvacrol has been considered as a biocidal resulting in bacterial membrane perturbations that lead to the leakage of intracellular ATP and potassium ions and ultimately cell death [59]. More, synergism between carvacrol and its precursor $p$-cymene has been noted. Ultee et al. (2002) proved that $p$-cymene is a very weak antibacterial, and swells bacterial cell membranes to a greater extent than carvacrol does. By this mechanism, $p$-cymene probably enables carvacrol to be more easily transported into the cell. So that a synergistic effect is achieved when the both are used together [60]. However, it was also considered that minor components, as well as a possible interaction between the substances could also affect the antimicrobial activities. In fact, other constituents, such as $\gamma$-terpinene, have been considered to display relatively good activity due to their possible synergistic or antagonistic effects [61]. Furthermore, in this sense, Cristani et al. (2007) studied the antimicrobial 
efficacy of four monoterpenes (thymol, carvacrol, $p$-cymene, and $\gamma$-terpinene) against the Gram-positive bacterium Staphylococcus aureus and the Gram-negative bacterium Escherichia coli and have demonstrated the efficacy of these compounds [62].

\subsubsection{Antibacterial activity of essential oils extracted from hydrolats.}

The significant bioactivity of the essential oil extracted from Thymbra capitata hydrolat is related to its high content of phenol: thymol $(4.36 \%)$, carvacrol $(75.14 \%)$ and 4-tert-butylcatechol $(14.72 \%)$ with an overall percentage of $(94.22 \%)$. This oil inhibited all bacterial strains tested at a concentration of MIC $=0.031 \mathrm{v} / \mathrm{v}($ Table $3)$.

However, the interactions between the various components of the oil can also affect their activity. The efficacy of the essential oil of Thymus against $S$. aureus is due to synergy between its main components especially carvacrol and thymol [63]. Moreover, several studies have pointed to the antimicrobial activity of carvacrol and thymol against E. coli O157: $H 7$ in in-vitro experiments [64-66]. These two compounds disintegrate the outer membrane of $E$. coli O157: $H 7$ and release outer membrane-associated material from the cells to the external medium [67]. On the other hand, Gill et al.(2006) have proved that carvacrol inhibited E. coli by inhibiting ATPase activity and disrupting the membrane [68]. Also, the effect of carvacrol on Staphylococus was investigated by Knowles et al. (2005) [69], this latter is consistent with our results in the case of the essential oil extracted from the Thymus glandulosus hydrolat, which consists mainly of three phenolic compounds: thymol (44.68\%), carvacrol $(45.95 \%)$ and 4-tert-butylcatechol $(3.87 \%)$ with an overall rate of $94.5 \%$ (Table 2) inhibiting all bacterial strains tested in concentration of MIC $=0.062 \mathrm{v} / \mathrm{v}$ (Table 3).

The value of an essential oil based on all of its components and not only to its major compounds [70], that may explain the biological potential of the essential oil extracted from the Thymus munbyanus hydrolat consists mainly of carvacrol (36.94\%), along with some oxygenated components: thymoquinone (10.79\%), borneol (10.21\%), linalyl anthranilate $(15.78 \%)$, camphor $(5.38 \%)$ and $\beta$-guaiene $(3.65 \%)$ (Table 2). This oil exerted a strong antibacterial activity. In contrary, both Gram- positive strains, inhibited at a concentration of $(\mathrm{MIC}=0.062$ $\mathrm{v} / \mathrm{v}$ ), appeared to be less sensitive than those Gram-negative which were inhibited from (MIC $=0.031 \mathrm{v} / \mathrm{v}$ ), considering that the type of bacteria has an influence on the effectiveness of the essential oils and Gram-negative bacteria were generally less susceptible than Gram-positive strains [71-73]. The difference in susceptibility of the bacteria to an essential oil is thought to arise as a result of the differences in their cell membrane structure. The cell envelopes of Gram-negative bacteria are more complex than the cell wall of Gram-positive bacteria. Gram-negative bacteria are composed of two layers that protect the cell and provide rigidity. Gram- positive bacteria lack the outer membrane, and that is maybe the reason why they would be more susceptible to action of phenolic components of essential oils [74]. Contrary to this hypothesis, Zayyad N. et al. (2014) showed that the Gram-positive bacteria of Erwinia Chrysanthemi was more resistant than several Gram-negative strains against essential oils of some species of Thymus [75], which is in harmony with our results for the extracted essential oil from the Thymus munbyanus hydrolat against bacterial strains tested.

From the results obtained, the antibacterial effect of the extracted essential oil from the Thymbra capitata hydrolat is greater than that exerted by the corresponding pure essential oil, and that is probably due to the richness of extracted oil from hydrolat in phenolic compounds: carvacrol (75.14\%), 4-tert-butylcatechol (14.72\%) and thymol (4.36\%) totaling $94.22 \%$ of the oil, while the phenolic compounds are represented in the pure essential oil by the single carvcrol $(85.35 \%)$.

In addition, the phenolic compounds enrichment of extracted essential oil from the Thymus glandulosus hydrolat [carvacrol (45.95\%), thymol (44.68\%) and 4-tert-butylcatechol (3.87 \%)] compared to the corresponding pure essential oil [carvacrol $(24.88 \%)$ and thymol $(28.51 \%)$ ], imposed a difference in efficacy of antibacterial power in favor of the extracted essential oil from hydrolat in comparison with the corresponding pure essential oil.

The difference observed between the antibacterial effect of the extracted essential oil from the Thymus munbyanus hydrolat against the bacterial strains tested and that exerted by the corresponding pure essential oil, is due to the richness of extracted essential oil from the hydrolat in oxygenated compounds and the synergy between them [linalyl anthranilate (15.78\%), borneol (10.21\%), thymoquinone (10.79\%) and camphor (5.38\%)] (Table 2).

The antimicrobial activities of the essential oils are difficult to associate to a specific compound due to their complexity and variability. Thus, the antimicrobial activity might be produced by the major compounds of the essential oils or due to a synergistic effect between the major compounds and the minor ones [76]. Nevertheless, some studies reported that there is a relationship between the chemical composition of the most abundant components in the essential oil and the antimicrobial activity [77]. Additionally, in the antimicrobial action of essential oil components, the lipophilic character of their hydrocarbon skeleton and the hydrophilic character of their functional groups are of the main importance [78]. The activity rank of essential oil components is as follows: 
phenols > aldehydes > ketones > alcohols > ethers > hydrocarbons [79]. Guarda et al. (2011) showed that the antimicrobial nature of essential oils is related to their high phenolic content especially thymol and carvacrol . They proved that the effectiveness of oils is proportional to their content of phenolic compounds [80]. Pinto et al. (2006) reported the species of the genus Thymus containing a significant amount of phenols, have a broad spectrum of activity against bacterial and fungal germs [81], which may explain our results.

\subsubsection{Minimum bactericide concentrations $(M B C)$.}

Based on the results obtained in this study as reported in table 3, the minimum bactericidal concentrations of the pure essential oils of these plant species are almost the same $(\mathrm{CMB}=0.125 \mathrm{v} / \mathrm{v})$ against all bacterial strains tested except in the case of the bacterial strain B.subtilis having CMB $=0.062 \mathrm{v} / \mathrm{v}$ for both pure essential oils of Thymbra capitata and Thymus glandulosus.

Furthermore, the extracted essential oil from Thymbra capitata hydrolat showed a major bactericidal power against the bacterial strains tested $(\mathrm{MBC}=\mathrm{MIC}=0.031 \mathrm{v} / \mathrm{v})$. The same for the extracted essential oil from the Thymus glandulosus hydrolat which showed a great bactericidal power against both Gram-negative strains $(\mathrm{CMB}=$ $\mathrm{MIC}=0.0625 \mathrm{v} / \mathrm{v})$, while its minimum bactericidal concentration $(\mathrm{MBC})$ against both Gram-positive strains was rather less than MIC.

In contrast, for the extracted essential oil from the Thymus munbyanus hydrolat, we noticed that the minimum bactericidal concentration $(\mathrm{MBC}=0.125 \mathrm{v} / \mathrm{v})$ is strictly lower than the minimum inhibitory concentration $[(\mathrm{MIC}=0.031 \mathrm{v} / \mathrm{v})$ for Gram-negative strains and $(\mathrm{MIC}=0.062 \mathrm{v} / \mathrm{v})$ of Gram-positive strains $]$.

\section{Conclusion}

The performed chemical analysis have been addressed to reveal that pure essential oils and extracted oils from hydrolats of three Thymus species studied (Thymbra capitata, Thymus munbyanus and Thymus glandulosus) were characterized by high contents of oxygenated monoterpenes especially both phenols carvacrol and thymol. There were some oxygenated compounds which are present in extracted oils from hydrolats, while they were totally or almost absent in corresponding pure essential oils [4-tert-butylcatechol (14.72\%) in hydrolat oil of Thymbra capitata and (3.87\%) in hydrolat oil of Thymus glandolosus; thymoquinone (10,79\%), borneol (10.21\%), linalyl anthranilate $(15,78 \%)$ and camphor $(5.38 \%)$ in hydrolat oil of Thymus munbyanus].

The results obtained have also shown highest antibacterial effect of all oils against the bacterial strains tested. Moreover, extracted oils from hydrolats showed an antibacterial power much greater than that exerted by the corresponding pure essential oils. This superiority is due to its richness in phenolic and oxygenated compounds comparing to the corresponding pure essential oils.

Thus, this work revealed that the pure essential oil of Thymbra capitata was the most effective against the bacterial strains tested compared with Thymus glandulosus and Thymus munbyanus pure essential oils which have almost the same antibacterial power, and this is due to its richness in phenolic carvacrol $(85.35 \%)$. Likewise, the antibacterial effect exerted by the extracted essential oil from Thymbra capitata hydrolat, rich in phenolic compounds [carvacrol (75.14\%) and 4-tert-butylcatechol (14.72\%)], is superior to those of the extracted oils from Thymus glandulosus and Thymus munbyanus hydrolats which showed almost the same antibacterial power.

Generally, the results obtained in this study support the richness and variability of Moroccan thyme. And the Thymbra capitata show an antibacterial power against the four bacterial strains tested superior than those of two other species (Thymus glandulosus and Thymus munbyanus).

\section{References}

1. J.G. Fouché, A. Marquet et A. Hambuckers, Observatoire du Monde Des Plantes Sart-Tilmam. Université de Liège Sart- Tilmam B77 (2000).

2. A.C. Dweck, Personal Care Magazine, 3(2) (2002) 19-21.

3. Kahouadji M.S., Thèse de troisième cycle. Université Mohammed I. faculté des sciences, Oujda (1995) 206.

4. Rejdali M., Actes. éd., (1996) 17-22.

5. Tantaoui-ElarakI A., Lattaoui N. ,et Errifi A. , J. Essent. Oil. Res., 5(1993a) 45-53.

6. Tantaoui-Elaraki A., Errifi A., Benjilali B.,and Lattaoui N. ,Rivista Italiana, 6(1992)13-23.

7. Hmamouchi M., Hamamouchi J., Zouhdi M., Bessiere J.M., J. Essent. Oil. Res.,13(4)(2001)298-302.

8. Settaf A., El Kabbaj S., Labhal A., Cherrah Y., Slaoui A. ,and Hassar M., Biologie \& Santé., 1(1)( 2000) 44-49.

9. Bellakhdar J., Edit. Ibis Press, Saint-Etienne, (1997) 764 .

10. Naghibi F., Mosaddegh M., Motamed S.M., and Ghorbani A., IJPR, 4(2) (2005) 63-79.

11. Stahl-Biskup E., Saez F., Edit. Thyme: The genus Thumus, Taylor and Francis, London, (2002) 1-43.

12. Brandão M.G.L., Cosenza G.P., Moreira R.A., Monte-Mór R.L.M. , Rev. Bras. Farmacogn., 16 (2006) 408-420 
13. Richard H., Benjilali B., Banquour N., et Baritaux O., Lebensm. Wiss. Technol. J.., 18 (1985) 105-110.

14. Papageorgio V., Planta Med. J., 40 (1980) 29-33.

15. Baser K.H.C., Ozek T. and Tumen G., J. Essent. Oil Res., 4 (1992) 659-661.

16. Baser K.H.C., Kirimer N., Tumen G. and Duman H., J. Essent. Oil Res., 10 (1998) 199-200.

17. Vila R., Freixa B., and Canigueral S., Flavour Flagr. J., 10 (1995) 379-383.

18. Guillen M.D., and Manzanos M.J., Food Chem. J., 3 (1998) 373-383.

19. Loziene K., Vauciunine J. and Venskutonis P., Planta Med. J., 64 (1998) 772-773.

20. Saez F., J. Herbs Spices Med. Plants, 5(1998) 65-76

21. Tumen G., Baser K.H.C., Demirci B. and Ermin N., Flavour Fragr. J., 13(1) ( 1998) 65-67.

22. Meister A, Bernhardt G, Christoffel V, and Buschauer A. , Planta Med J., 65 (1999) 512-516.

23. Essawi T. and Srour M., J. Ethnopharmacol.,70 (2000) 343-349

24. Dob T., Dahmane D, Benabdelkader T., and Chelghoum C., Int. J. Aromather., 16 (2006) 95-100.

25. Agnihotri S. and Vaidy A.D.B., Indian J. Exp. Biol., 34(7) ( 1996) 712-715.

26. Soliman KM, Badeaa RI, Food Chem. Toxico. J., 40 (2002) 1669-1675.

27. Pellecuer J., Jacob M., Simeon de Buechberg M., and Allegrini ,J., Acta Hortic., 96(1980 ) 35-39.

28. Carlini EA., Rodrigues E., Mendes FR.,Tabach R,and Gianfratti B , Rev. Bras. Farmacogn., $16(2006$ ) 690695.

29. Tepe B., Sokmen M., Akpulat HA., Daferera D., Polissiou M., and Sokmen A., J. Food Eng., 66(2005 ) 447454.

30. Bhaskara M.V., Angers P., Gosselin A.,and Arul J., phytochemistry J.,47(1998)1515-1520.

31. Benabid A., Edit Ibis Press Paris, (2000)159-161.

32. Bellakhdar J., Edit. Ibiss press Paris , (1996) 358.

33. Sijelmassi A., Edit. Le Fennec, Casablanca, (1993) 286.

34. Ismaili H., Tortora S., Sosa S., Fkih-Tetouani S., Ilidrissi A., Della Loggia R.,Tubaro A., and Aquino R., J. Pharm. Pharmacol.,53(2001 )1645-1652.

35. Ismaili H., Sosa S., Brkic D., Fkih-Tetouani S., Ilidrissi A.,Touati D., Aquino R., and Tubaro A., J. Pharm Pharmacol.,54(2002) 1137-1140.

36. Ismaili H., Milella L., Fkih-Tetouani S., Ilidrissi A., Camporese A., Sosa S., Altinier G., Della Loggia R., and Aquino R.,J. Ethnopharmacol., 91(2004) 31-36.

37. Benjilali B., Hammouni M., M'hamdi A. and Richard H., Sci. Aliment. J., 7(1987a )275-299.

38. Benjilali B., Hammouni M. and Richard H., Sci. Aliment. J., 7(1987b) 77-91.

39. Catty S., Healing Arts Press. Rochester., (2001)290 .

40. Price L. and Price S., First Edit. Churchill Livingstone, (2004) 294.

41. Jeannot V., Chahboun J., Russel D., and Casablanca H., Int. J. Aromather,13(2003) 90-94.

42. Bouhdid S., Skali S. N., Idaomar M., Zhiri A., Baudoux D., Amensour M. and Abrini J., Afr. J. Biotechnol., 7 (10) (2008)1563-1570

43. Bounatirou S., Smiti S., Miguel M.G., Rejeb M.N., Nefati M., Costa M.M., Faleiro L., Figueiredo A.C., Baroso J.G., and Pedro L.G., Food Chem.J., 105(2007) 146 - 155.

44. Ibraliu, A., Mi, X., Risti, M., Dajic S. Z., and Shehu, J., J.Med. Plants Res., 51(2011) 58-62.

45. Salas J. B. ,Téllez T. R., Alonso M. J. P., Pardo F. M. V., Capdevila M. D. L. Á. C. and Rodríguez C. G., Acta Bot.Gallica J.,157(1)( 2010) 55-63.

46. Goren A.C., Bilsel G., Bilsel M., Demir H., and Kocabas E.E., Z. Natuforsch.. J., 58(9-10)( 2003) 687-690.

47. Cosentino S., Tuberoso C.I.G., Pisano B., Setta M., Mascia V., Arzidi E. and Palmas F., Lett. Appl. Microbiol., 29(2)( 1999)130-135.

48. Adzet T., Vila R. and Canigueral S., Flavour and Fragr. J., 4(1989) 133-134.

49. Chebli B., Achouri M., Idrissi Hassani L.M., and Hmamouchi M., Fr. J. Ethnopharmacol., 89 (2003) 165-169.

50. Benchabane O., Hazzit M., Baaliouamer A. and Mouhouche F., J. Essent. Oil Bear. Pl., 15 (5) (2012) 774- 781.

51. Belmalha S., El idrissi M., Amechrouq A. et Echchgadda G., G.J.P.A.C.R., 3(2) ( 2015) 43-52.

52. Bell G. and Lechowicz M. J. , J. Eco., 79(1991)663-685.

53. Tarayre M., Thompson J.D., Escarré J. and Linhart Y.B., Oecologia J., 101(1) ( 1995) 110-118.

54. Gouyon P. H.,Vernet P., Guillern J.L., and Valdeyron G. , Heredity J., 57 (1986) 59-66.

55. Duke J. A., phytochemical Data base.USDA-ARS-NGRL Edit. Beltville Agricultural Research center, Belstville, Maryland (1998) .

56.Amarti F., Satrani B., Ghanmi M., Farah A., Aafi A., Aarab L., El Ajjouri M., Chaouch A., J. Biotechnol. Argon.soc. Environ.,14(1) ( 2010) 141-148. 
57. Boukhatem M. N., Ferhat M. A., Kameli A., Saidi F., Taibi H., and Teffahi D.,I.J.I.A.S , 8 (4) ( 2014) 14181431

58. Bouzouita N., Kachouri F., Hamdi M., \& Chaabouni M. M. ,Flavour and Fragrance J., 18 (2003) 380383.

59. Ultee A., Kets E.P.W., and Smid E.J., J.Appl. Environ. Microbiol., 65 (1999) 4606 - 4610.

60. Ultee A., Bennik M.H.J., and Moezelaar R., J. Appl. Environ. Microbiol., 68 (2002) 1561 - 1568.

61. Vardar-Unlu G., Candan F., Sokem A., Daferera D., Polissiou M., and Sokmen M., J. Agric. Food. Chem. J. , 51 (2003) 63-67.

62. Cristiani M., D’Arrigo M., Mandalari G., Castelli F., Sarpietro M. G., Micieli D., Venuti V., Bisignano G., Saija A. and Trombetta D. , J. Agric. Food Chem., 55 (2007) $6300-6308$.

63. Lambert R. J. W., Skandamis P. N., Coote P. J. and Nychas G. J., J. Appl. Microbiol., 91(3) ( 2001) 453-462.

64. Ben Hammou F., Skali S.N., Idaomar M., and Abrini J. , Afr. J. Biotechnol., 10(71) ( 2011) 15998-16005.

65. Di Pasqua R., Hoskins N., Betts G., and Mauriello G., J. Agric. Food Chem., 54 (2006 ) 2745-2749.

66. Burt S.A., Vlielander R., Haagsman H.P., and Veldhuizen E.J.A. ,J. Food Prot., 68(5) ( 2005) 919-926.

67. Helander I.M., Alakomi H.L., Latva-Kala K., Mattila-Sandholm T., Pol I., Smid E.J., Gorris L.G.M., and Von Wright A., J. Agric. Food Chem., 46 (1998) 3590-3595.

68. Gill A.O., and Holley R.A., Int. J.Food Microbiol., 108(1) ( 2006) 1-9.

69. Knowles J. R., Roller S., Murray D. B. and Naidu A.S., J. Appl. Environ. Microbiol.,71 (2005) 797- 803.

70. Lahlou M., J. Phytother. Res., 18(6)( 2004)435-448.

71. Gilles M., Zhao J., An M., and Agboola S., Food Chem. J. ,119 (2) ( 2010) 731-737.

72. Wan J., Wilcock A., and Coventry M.J.,Appl. Microbiol., 84 (1998) 152-158.

73. Inouye S., Yamaguchi H., and Takizawa T., J. Infect. Chemother., 7 (2001) 251-254.

74. Angienda P.O., Onyango D.M., and Hill D.J., Afr. J. Microbiol. Res., 4 (2010) 1678-1684.

75. Zayyad N., Farah A. et Bahlou J., Bull. Soc. Roy. Sci. Liège, 83 (2014) 118-132.

76. Carovic-Stanko K., Orlic S., Politeo O., Strikic F., Kolak I., Milos M., and Satovic Z., Food Chem. J., 119 (2010) 196-201.

77. Djenane D., Yangüela J., Montãnés L., Djerbal M., Roncalés P., Food Control. J., 22(7) ( 2011) 1046-1053.

78. Nowak A., Kalemba D., Krala C., Piotrowska M., and Czyzowska A., Food Microbiol. J., 32(2012) 212-216.

79. Kalemba D., and Kunicka A., Curr. Med. Chem. J.,10(2003) 813-829.

80. Guarda A., Rubilar J. F., Miltz J. and Golotto J. , Int. J. Food Microbiol.,146(2) (2011)144-150.

81. E. Pinto, C. Pina-Vaz, L. Salgueiro, M.J. Gonçalves, J. Martinez-de-Oliveira, J. Med.Microbiol., 55(10) (2006) 1367-1373.

(2018) ; http://www.jmaterenvironsci.com 